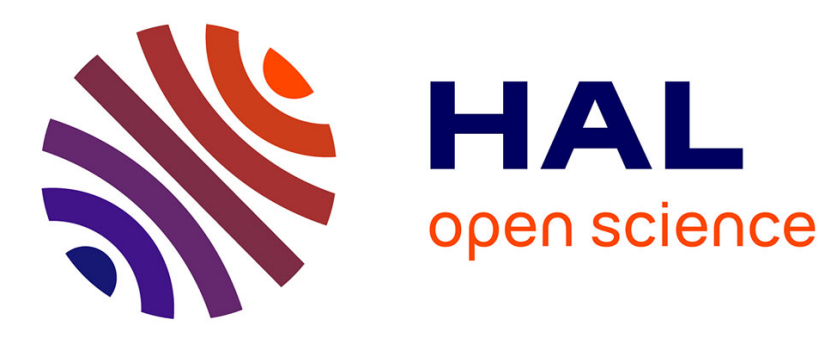

\title{
Further insights into the growth mechanism of the non-stoichiometric $\theta$-Ni2Si phase
}

\author{
G. Tellouche, D. Mangelinck, K. Hoummada, A. Derafa
}

\section{To cite this version:}

G. Tellouche, D. Mangelinck, K. Hoummada, A. Derafa. Further insights into the growth mechanism of the non-stoichiometric $\theta$-Ni2Si phase. Vacuum, 2021, 187, pp.110075. 10.1016/j.vacuum.2021.110075 . hal-03452320

\section{HAL Id: hal-03452320 \\ https://hal.science/hal-03452320}

Submitted on 26 Nov 2021

HAL is a multi-disciplinary open access archive for the deposit and dissemination of scientific research documents, whether they are published or not. The documents may come from teaching and research institutions in France or abroad, or from public or private research centers.
L'archive ouverte pluridisciplinaire HAL, est destinée au dépôt et à la diffusion de documents scientifiques de niveau recherche, publiés ou non, émanant des établissements d'enseignement et de recherche français ou étrangers, des laboratoires publics ou privés.

\section{(ㅇ)(1) $\$$}

Distributed under a Creative Commons Attribution - NonCommercial - NoDerivatives $\mid 4.0$ 
Further insights in the growth mechanism of the non-stoichiometric $\theta-\mathrm{Ni}_{2} \mathrm{Si}$ phase

G. Tellouche ${ }^{1}$, D. Mangelinck ${ }^{2}$, K. Hoummada ${ }^{2}$, A. Derafa ${ }^{3}$

1- Laboratoire CMI, Faculté des Sciences Exactes, Université Constantine 1, Algérie

2- IM2NP, Aix Marseille, CNRS, Case 142, 13397 Marseille, France

3- Laboratoire LP3M, Université de Sétif19000, Algérie

\section{Abstract:}

The solid state reaction of $50 \mathrm{~nm} \mathrm{Ni}$ with $\mathrm{Si}(100)$ substrate was investigated using in situ X-ray diffraction (XRD). The sequence is simultaneous; it begins by $\delta-\mathrm{Ni}_{2} \mathrm{Si}$ phase then the metastable $\theta-\mathrm{Ni}_{2} \mathrm{Si}$ phase is formed. Both phases grow simultaneously. The growth mechanism of the nonstoichiometric $\theta-\mathrm{Ni}_{2} \mathrm{Si}$ phase is discussed on the basis of the evolution of its XRD peak during annealing. The results show that, during its growth, the non-stoichiometric $\theta-\mathrm{Ni} 2 \mathrm{Si}$ phase is split into two regions of different concentrations. This "original" behavior is justified by the discontinuous variation with composition of both the diffusion coefficient and the d-lattice spacing through the $\theta-\mathrm{Ni}_{2} \mathrm{Si}$ phase.

Key words: diffusion coefficient, non-stoichiometric phases, lattice spacing.

\section{Introduction}

Owing to the beneficial properties of NiSi silicide (low contact and sheet resistance, low formation thermal budget), it is so far the promising candidate for application in microelectronic devices.

The formation of NiSi phase, via solid state reaction between Ni film $\left(e_{c}>4,8 \mathrm{~nm}\right)$ and $\mathrm{Si}(100)$, is preceded by a simultaneous formation of Ni-rich phases [1]. Recent studies have shown that the sequence of Ni-rich phases and their characteristics (texture, resistivity and interface quality) is altered by the substrate orientation [2], film thickness [1,3,4], the presence of dopants [5] and alloy elements [1,6,7]. The formation of Ni-rich phases is albeit evidenced for all preparation conditions. Their identification has been the subject of several investigations $[8,9,10]$. Nevertheless, it is complicated by the fact that most Ni-rich phases have relatively low symmetry (except cubic $\mathrm{Ni}_{3} \mathrm{Si}$ ) which results in a multitude of possible XRD peak position, many of which are common to different phases. It was reported that the formation of $\mathrm{Ni}_{3} \mathrm{Si}_{2}$ from $\mathrm{Ni}_{2} \mathrm{Si}$ and $\mathrm{NiSi}$, was attributed to the destabilization of $\delta-\mathrm{Ni}_{2} \mathrm{Si}$ by the surface energy when 
it becomes too thin. The formation of $\mathrm{Ni}_{31} \mathrm{Si}_{12}$ is observed during faster ramp annealing of thick Ni film $(\mathrm{e}=500 \mathrm{~nm})$ deposited on c-Si [9].

Using sophistical probes as X-ray pole figure measurements, scrutiny has led to significant knowledge [9]. In particular, the metastable $\theta-\mathrm{Ni}_{2} \mathrm{Si}$ has been shown to form at low temperature at the $\delta-\mathrm{Ni}_{2} \mathrm{Si} / \mathrm{Si}$ interface. Its formation at low temperature has been attributed to a lower nucleation barrier resulting from a combination of the texture inheritance and/or epitaxy and the ability of the non-stoichiometric $\theta$ phase to nucleate in the strong composition gradient present at the interface [9]. The $\theta-\mathrm{Ni}_{2} \mathrm{Si}$ phase is normally stable above $825^{\circ} \mathrm{C}$ of hexagonal structure, the lattice parameters decrease with the enrichment in $\mathrm{Si}$ of $(\mathrm{a}=3.836 \mathrm{~A}$ and $\mathrm{c}=$ 4.948A) for 37.5at.\% Si to $(\mathrm{a}=3.802 \mathrm{~A}$ and $\mathrm{c}=4.863 \mathrm{~A})$ for $43 \mathrm{at} . \% \mathrm{Si}[11]$. This composition range is restricted at low temperature to $38,5-43 \mathrm{at} . \% \mathrm{Si}$ [9]. Few data about the $\theta-\mathrm{Ni}_{2} \mathrm{Si}$ growth kinetic are available in literature. The growth of $\theta-\mathrm{Ni}_{2} \mathrm{Si}$ is of interface control; the growth rate is of $10 \exp (-0,85 \mathrm{eV} / \mathrm{kT}) \mathrm{cm} / \mathrm{sec} 10]$. However, diffusion may play a role on its growth mechanism. Indeed, it was observed that $\theta-\mathrm{Ni}_{2} \mathrm{Si}$ forms during isothermal annealing at lower temperature $\left(180^{\circ} \mathrm{C}\right)[4,5]$ than that reported, in several investigations during isochronal annealing $\left(280^{\circ} \mathrm{C}\right)$ for different preparation conditions $[1,2,6]$.

In this article, the growth mechanism of the non-stoichiometric $\theta-\mathrm{Ni}_{2} \mathrm{Si}$ phase was investigated. Thanks to the in situ-XRD measurements one can assess, as a first approximation, the variation of both the XRD intensity and the lattice parameter of the $\theta-\mathrm{Ni}_{2} \mathrm{Si}$ phase versus $\mathrm{Ni}$ concentration.

\section{Experimental procedure:}

$\mathrm{Ni}$ films of 50nm thick were deposited by magnetron sputtering on Si substrates with (100) orientation. Prior to deposition, the substrates were cleaned in a dilute 5\% HF solution to remove the native oxide. The deposition was performed in a sputtering chamber with a base pressure of $10^{-8}$ Torr using 99,999\% pure Ar gas flow and a 99,99\% pure Ni target. The wafer was rotating during deposition to improve the homogeneity of the layer. In situ-XRD measurements were performed during annealing which was performed in vacuum ambient of about $10^{-5}$ mbarr. (. In situ analyses were performed after ramping from room temperature to $200^{\circ} \mathrm{C}$ with a rate of $35^{\circ} \mathrm{C} / \mathrm{min}$. The temperature was then increased by step of $5 \mathrm{~K}$ until $920^{\circ} \mathrm{C}$ and the temperature was kept constant during the XRD measurements that lasted typically two 
minutes. The $2 \theta$ interval was selected from $\left(30^{\circ}\right.$ to $\left.50^{\circ}\right)$ since it contains the characteristic $\mathrm{x}-$ ray diffraction peaks for the important phases in $\mathrm{Ni}-\mathrm{Si}$ system.

\section{Results}

Figure 1 shows the result of XRD (three dimensional views) measurements during the reaction of $50 \mathrm{~nm} \mathrm{Ni}$ film with $\mathrm{Si}(100)$ from 200 to $920^{\circ} \mathrm{C}$.

XRD spectra show that the reaction initiates, around $200^{\circ} \mathrm{C}$, with the formation of the $\delta-\mathrm{Ni}_{2} \mathrm{Si}$ (211) and (020) phase. An additional peak appears around $47^{\circ}$ attributed to $\theta-\mathrm{Ni}_{2} \mathrm{Si}$ (110) peak. In agreement with previous investigations, only one XRD peak is attributed to this phase [2,9]. We observe that the $\theta-\mathrm{Ni}_{2} \mathrm{Si}$ exists over a sharply temperature window $\left(280-350^{\circ} \mathrm{C}\right)$. Around $320^{\circ} \mathrm{C}$, the Ni film is fully consumed; a shift towards high angles is mentioned, on both $\theta$ and $\delta-\mathrm{Ni}_{2} \mathrm{Si}$ peaks due to stress relaxation. At this temperature, $\mathrm{NiSi}$ phase appears with multiple XRD peaks. Further heating leads to an increase in NiSi intensity peaks and a disappearance of the $\delta-\mathrm{Ni}_{2} \mathrm{Si}$ phase. As the temperature increases further, a weak XRD peak emerges around $47^{\circ}$ (the beginning of this peak is not clear) and this could be attributed to the $\mathrm{NiSi}_{2}$ phase. .

A zoom-in on the $\theta-\mathrm{Ni}_{2} \mathrm{Si}$ XRD peak is presented in figure 2. This peak has a striking behavior. During heating, several shifts of $\theta-\mathrm{Ni}_{2} \mathrm{Si}$ peak are observed: the first one towards high angles, and then an important shift towards low angle is observed with increasing temperature. When the $\mathrm{Ni}$ film is fully consumed the stress is relaxed and the $\theta-\mathrm{Ni}_{2} \mathrm{Si}$ peak shifts again towards high angles.

The first and the second shifts were already observed and attributed to the variation in composition due to different equilibrium at different interfaces during the reaction $[10,5]$. A close look on the $\theta$ - XRD peak (Figure2) reveals that it is not a simple shift, however the peak is also split into two peaks labelled $\theta 1-\mathrm{Ni}_{2} \mathrm{Si}$ and $\theta 2-\mathrm{Ni}_{2} \mathrm{Si}$.

This behavior is clearly depicted in 2D (right): the peaks are presented in order from low (peak1) to high annealing temperature (peak11), in particular pic 9 (red). The division of the $\theta$ $\mathrm{Ni}_{2} \mathrm{Si}$ XRD peak into two close peaks in two different Bragg positions is never reported in literature. Thus a deep analysis is required to identify the mechanisms behind the observed behavior. Isothermal annealing at low temperature $\left(180^{\circ} \mathrm{C}\right)$ are of interest, this type of annealing permits to slow-down the reactions hence to get more details on the evolution of the $\theta-\mathrm{Ni}_{2} \mathrm{Si}$ XRD peak. 
Figure 3(left) shows the evolution of the $\theta-\mathrm{Ni}_{2} \mathrm{Si}(110)$ XRD peak intensity during isothermal annealing at $180^{\circ} \mathrm{C}$. (The in situ XRD measurements performed from $\left(30\right.$ to $\left.50^{\circ}\right)$ are presented in references 4 and 5). The figure3(left) shows clearly that the XRD peak follows the same behavior mentioned during isochronal annealing: i.e. the $\theta-\mathrm{Ni}_{2} \mathrm{Si}(110)$ peak is split into two very close peaks in two Bragg positions

We present in figure 3(right) the variation of the lattice spacing of the (110) planes of the $\theta$ $\mathrm{Ni}_{2} \mathrm{Si}$ phase during isothermal annealing at $180^{\circ} \mathrm{C}$. For such isothermal annealing, the variation of $\mathrm{d}$-spacing should be originating from variation of composition through the $\theta-\mathrm{Ni}_{2} \mathrm{Si}$ phase. (). The $\mathrm{d}$-spacing is deduced from the Bragg's law: $d=\frac{\lambda}{2 \sin \theta}$.

Figure 3 (right) shows that the $\theta-\mathrm{Ni}_{2} \mathrm{Si}$ phase is stable over $1,5 \mathrm{~h}$ annealing at $180^{\circ} \mathrm{C}$. As $\mathrm{Ni}$ is the more mobile species, one can expect the same behavior of d-spacing versus Ni composition. The d-spacing of (110) planes of $\theta-\mathrm{Ni}_{2} \mathrm{Si}$ exhibits a minimum value of $1,917 \AA$ after $0,8 \mathrm{~h}$ annealing and increase to $1,924 \AA$ and to $1,928 \AA$ on both minimum sides over its time span (see Figure 3right). Such discontinuous variation of the lattice spacing is not without precedent; indeed the same behavior was mentioned during the formation of the non-stoichiometric $\mathrm{Ni}_{2} \mathrm{Al}_{3}$ phase [12].

\section{Discussion:}

The formation of Ni-rich phases via solid phase reaction requires a detailed understanding on the growth kinetics. We focus our attention on the non-stoichiometric $\theta-\mathrm{Ni}_{2} \mathrm{Si}$ phase; its growth mechanism cannot be investigated without considering the possibility of a varying composition during the reaction and the nature of the defects over the composition range of the $\theta-\mathrm{Ni}_{2} \mathrm{Si}$ phase. The growth of non-stoichiometric phases was first investigated for the intermetallic compounds $[13,14,12]$. The obtained results are then formalized by d'Herurle and Ghez as a simple model generally valid for all diffusive reactions in the solid state [15].

\section{a) Phase sequence}

The in situ XRD measurements (Fig.1) clearly indicate a simultaneous formation of only $\delta$ and $\theta-\mathrm{Ni}_{2} \mathrm{Si}$ phases, the latter grows by consuming $\delta-\mathrm{Ni}_{2} \mathrm{Si}$ and $\mathrm{Si}$. The $\theta-\mathrm{Ni}_{2} \mathrm{Si}$ phase is characterized by only the two (110) XRDpeaks centered at $47^{\circ}$. Nor $\mathrm{Ni}_{3} \mathrm{Si}_{2}$ neither $\mathrm{Ni}_{3} \mathrm{Si}$ were detected under these annealing conditions. When $\mathrm{Ni}$ is fully consumed, the NiSi phase grows by consuming both $\delta-\mathrm{Ni}_{2} \mathrm{Si}$ and $\theta-\mathrm{Ni}_{2} \mathrm{Si}$ phases. The $\mathrm{NiSi}_{2}$ is the last phase to form at high 
temperatures: it grows at the expense of $\mathrm{NiSi}$. The phase sequence mentioned is consistent with previous works on the reaction of different $\mathrm{Ni}$ thicknesses (e>4,8nm [1]) with $\mathrm{Si}(100)$ during isothermal and isochronal annealing $[1,2,5,9,10]$.

\section{b) The kinetic growth of $\theta-\mathrm{Ni}_{2} \mathrm{Si}$}

As depicted in Figure 2, the XRD peak of $\theta-\mathrm{Ni}_{2} \mathrm{Si}$ is split into two peaks in two close Bragg positions $\left(\theta_{1}-\mathrm{Ni} 2 \mathrm{Si}\right.$ and $\left.\theta_{2}-\mathrm{Ni}_{2} \mathrm{Si}\right)$. One may wonder about the origin of this behavior. It could be explained by the presence of two separate phases in thermodynamic equilibrium.

However as discussed above, only $\theta-\mathrm{Ni}_{2} \mathrm{Si}$ and $\delta-\mathrm{Ni}_{2} \mathrm{Si}$ phases precede the formation of $\mathrm{NiSi}$. No other Ni-rich phase forms. Hence, the two XRD peaks centered at $47^{\circ}$ should be attributed to the $\theta-\mathrm{Ni}_{2} \mathrm{Si}$ phase and could be originating from the growth mechanism of this phase.

Figure 3 shows the variation of (110) d-spacing planes of the two XRD-peaks of the $\theta$-Ni2Si phase during time annealing.. The minimum in d-spacing occurs at some intermediate $\mathrm{Ni}$ composition (corresponding to $\mathrm{t}=0,8 \mathrm{~h}$ ) which is unknown. It was also shown that the evolution of the lattice parameter of $\mathrm{Ni}_{2} \mathrm{Al}_{3}$ phase versus composition shows a minimum at offstoechiomtry $\mathrm{Ni}_{2} \mathrm{Al}_{3}$ [12]. On the other hand, the variation of the lattice parameter of the AlNi solid solution vs composition shows a maximum at also off-stoichiometry $\mathrm{NiAl}$ [13].

Our first interest is focused on the increase of d-spacing on both sides of the minimum of $\mathrm{d}$ spacing through the $\theta-\mathrm{Ni}_{2} \mathrm{Si}$ phase. The increase in d-spacing, which occurs after $0,8 \mathrm{~h}$ annealing, is expected on the $\mathrm{Ni}$ rich side of $\theta-\mathrm{Ni}_{2} \mathrm{Si}$ with an excess of $\mathrm{Ni}$ atoms.. On the other hand, the increase in $\mathrm{d}$-spacing observed in the Si-rich side $(\mathrm{t}<0,8 \mathrm{~h}$ annealing) is difficult to understand. This could be however possible when the small Si atoms are accommodated on interstitial sites; in the same way as it was reported in $\mathrm{Ni}_{2} \mathrm{Al}_{3}$ phase [12]. The discontinuous variation of lattice spacing may thus be due to different type of defects through the $\theta-\mathrm{Ni}_{2} \mathrm{Si}$ phase. The dependence of the lattice parameters on the defect nature was evidenced for intermetallic compounds $\mathrm{NiAl}[13]$ and $\mathrm{Ni}_{2} \mathrm{Al}_{3}$ [12].

It's important to underline that when the defect nature (vacancies and/or interstitial) are composition sensitive, they could have dramatic effects on the diffusion behavior [14]. This is 
indeed what the XRD measurements evidenced. The growth of the $\theta-\mathrm{Ni}_{2} \mathrm{Si}$ phase with two XRD peaks is certainly due to the split of the $\theta-\mathrm{Ni}_{2} \mathrm{Si}$ phase into sharply defined regions of different composition. Let us recall that, although the growth of $\theta-\mathrm{Ni}_{2} \mathrm{Si}$ is not purely controlled by diffusion, one can assume that the intensity of the XRD peaks could be representative, as first approximation, of the volume fraction of the $\theta-\mathrm{Ni}_{2} \mathrm{Si}$ phase which scales with diffusion coefficient D. Itis clear from figure 2, that the $\theta-\mathrm{Ni} 2 \mathrm{Si}$ XRD peak shows two intense peaks, separated by an intermediate zone with low intensity. This results from the variation of diffusion coefficient versus composition which goes through a minimum for an intermediate composition (see figure 4) in a similar fashion to $\mathrm{AgMg}[16], \mathrm{AuCd}[17], \mathrm{NiAl}[13,14]$ and $\mathrm{Ni}_{2} \mathrm{Al}_{3}[12,15]$ non-stoichiometric phases. The growth of the $\theta-\mathrm{Ni}_{2} \mathrm{Si}$ phase with two XRD peaks may appear as the growth of two phases but in fact correspond to the $\theta-\mathrm{Ni}_{2} \mathrm{Si}$ phase that is split into relatively sharply defined regions of different composition. The two regions represent regions of maximum diffusion coefficients. The variation in the diffusion coefficient leads thus to the discontinuous variation of d-spacing versus composition.. Indeed, the regions of maximum diffusion coefficient corresponding to high defect concentration regions. The $\theta-\mathrm{Ni}_{2} \mathrm{Si}$ phase with minimum of defect concentration should thus not appear since it has a low diffusion coefficient and will be "consumed" by high diffusion $\theta-\mathrm{Ni}_{2} \mathrm{Si}$ phase. .

We underline that a good agreement is evidenced between the discontinuous variation of lattice spacing and the intensity of the XRD peak of the non- stoichiometric $\theta-\mathrm{Ni}_{2} \mathrm{Si}$ phase, both of which reinforce the growing phase to appear as separate regions. A more quantitative understanding may be obtained by looking at different XR peaks using reciprocal space mapping techniques. . In addition, the growth mechanism of $\theta-\mathrm{Ni}_{2} \mathrm{Si}$ discussed could be sensitive to both preparation conditions (substrate orientation, the presence of dopants, thickness of deposited film and the presence of alloying elements...) and annealing conditions, thus further analysis is required to thoroughly characterize the $\theta-\mathrm{Ni}_{2} \mathrm{Si}$ phase.

\section{Conclusion:}

The solid state reaction of 50nmNi with $\mathrm{Si}$ (100) was followed by in situ XRD during isochronal annealing from 200 to $920^{\circ} \mathrm{C}$. The evolution of the XRD peaks intensities and lattice spacing of the non-stoichiometric $\theta-\mathrm{Ni}_{2} \mathrm{Si}$ phase allow us to deduce that $\theta-\mathrm{Ni}_{2} \mathrm{Si}$ is split into two defined regions of different composition separated by a zone corresponding to the minimum in the diffusion coefficient. 


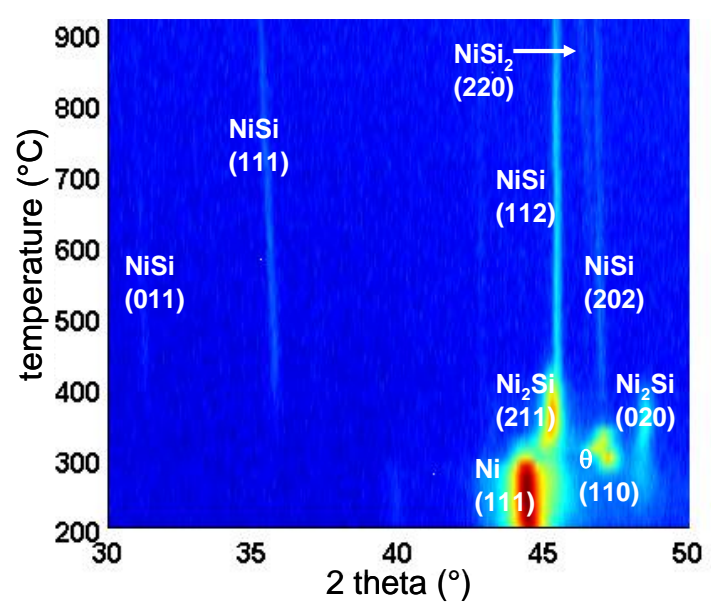

Figure1. In situ XRD measurements on $50 \mathrm{nmNi} / \mathrm{Si}(100)$ sample during thermal ramp at $35^{\circ} \mathrm{C} / \mathrm{min}$ from $200^{\circ} \mathrm{C}$ to $920^{\circ} \mathrm{C}$.

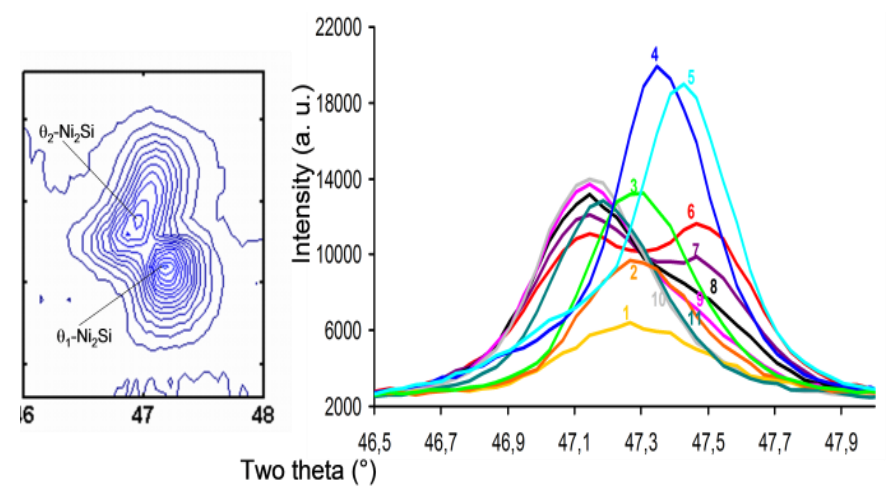

Figure2. (Left) Zoom-in on the XRD peak of the $\theta-\mathrm{Ni}_{2} \mathrm{Si}$ phase from figure 1. (Right) Evolution of $\theta-\mathrm{Ni}_{2} \mathrm{Si}$ peaks (2D) during heating: from low temperature (peak1) to high temperature (peak11).
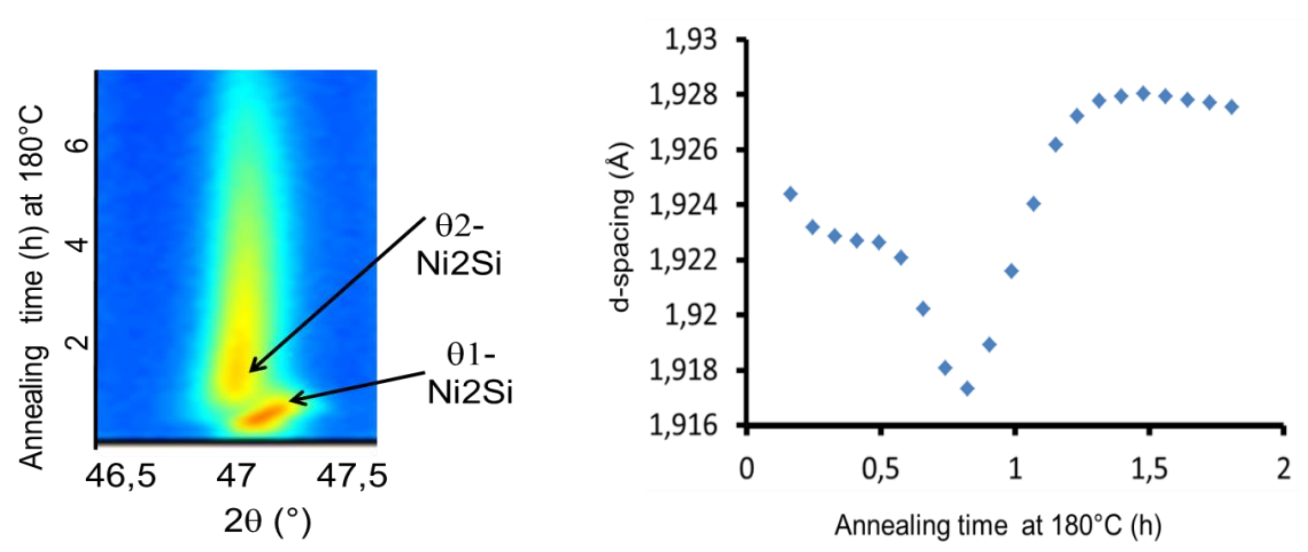

Figure3. (Left) the evolution of the XRD peak of the $\theta-\mathrm{Ni} 2 \mathrm{Si}$ phase during isothermal annealing at $180^{\circ} \mathrm{C}$. (Right) The variation of $\theta-\mathrm{Ni}_{2} \mathrm{Si}$ lattice spacing during isothermal annealing at $180^{\circ} \mathrm{C}$. 


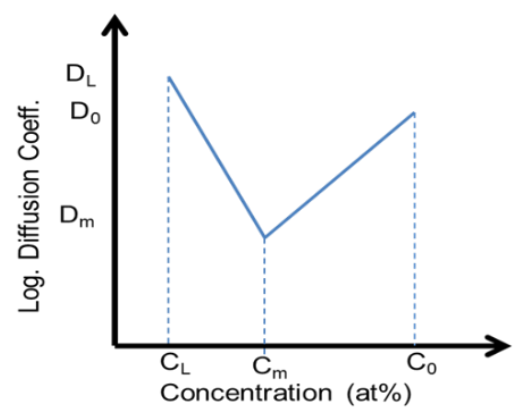

Figure 4. Schematic representation of the variation of the diffusion coefficient as a function of composition in phases such AlNi [15].

\section{References:}

${ }^{1}$ F.A. Geenen, K. van Stiphout, A. Nanakpudis, S. Bals, A. Vantomme, J. Jordan -Sweet, C. Lavoie and C. Detavernier, J. App. Phys. 123(2018) 075303.

${ }^{2}$ S. Gaudet, P. Desjardin and C. Lavoie, J. App., Phys. 110 (2011) 113524

${ }^{3}$ K. De Keyser, C. Van Bockstael, R. L. Meirhaeghe and C. Detavernier, App. Phys. Lett. 96 (2010) 173503

${ }^{4}$ G. Tellouche, K. Hoummada, A. Derafa, I. Blum, A. Portavoce, D. Mangelinck, Microelectron. Eng. 120, (2014) 146.

${ }^{5}$ G. Tellouche, A. Derafa, K. Hoummada and D. Mangelinck, Vacuum, 141 (2017) 259.

${ }^{6}$ A. Derafa, G . Tellouche, K. Hoummada, A. Bouabellou, D. Mangelinck, Microelectron. Eng. 120 (2014) 150

${ }^{7}$ F. A. Geenen, E. Solano, J. Jordan, Sweet, C. Lavoie, C. Mocuta and C. Detavernier, J. App. Phys. 123 (2018) 185302

${ }^{8}$ C. Lavoie, C. Coia, F. M. d'Heurle, C. Detaveernier, C. Cabral, Jr. P. Desjardin, A. J. Kellock, Defect Diff. Forum 237 (2005) 825.

${ }^{9}$ S. Gaudet, C. Coia, P. Desjardin and C. Lavoie, J. App. Phys 107 (2010) 093515.

${ }^{10}$ D. Mangelinck, K. Hoummada, I. Blum, App. Phys, Lett. 95 (2009) 181902.

${ }^{11}$ P. Nash and A. Nash, Bulletin of Alloy Phase Diagrams, 8 (1987) 6.

${ }^{12}$ A. Taylor and N. J. Doyle, J. Cryst. 5 (1972) 201.

13 A. J. Bradley and A. Taylor, Philos. Mag., 23 (1937) 1049.

${ }^{14}$ G. F. Hancock and B. R. Mc Donnell, Phys. Stat. Sol. (a)4 (1971).

${ }^{15}$ F. M. d'Heurle and R. Ghez, Thin Solid Films 215 (1992) 19

${ }^{16}$ W. C. Hagel and J. H. Westbrook, Diffusion in B. C. C. Metals, A.S.M. 1965

${ }^{17}$ D. Gupta, D. Lazarus and D. S. Liberman, Phys. Rev. 153 (1967) 863. 